\title{
A Study of Early Childhood Development Teachers' Experiences in Zimbabwe: Implications to Early Intervention and Special Education
}

\author{
Arnold Nyarambi \\ East Tennessee State University, Johnson City, UNITED STATES \\ Clemmer College of Education \\ Esther Ntuli \\ Idaho State University, Pocatello, UNITED STATES \\ College of Education
}

Received: 3 March 2020 • Accepted: 25 May 2020 • Published Online: 30 June 2020

\begin{abstract}
This study examined Early Childhood Development (ECD) teachers' perceptions of ECD programs regarding benefits and opportunities for early intervention. Research indicates that young children with developmental delays and disabilities demonstrate better progress when intervention is offered early and in inclusive classrooms. A mixed method design was used to collect data from a purposeful sample of $81 \mathrm{ECD}$ teachers in Chipinge district, in Zimbabwe. Both descriptive and regression analysis methods were used for data analysis. Findings indicated that there was a general lack of in-depth knowledge, and most teachers did not follow developmentally appropriate curriculum. Threats and challenges included: lack of knowledge and assessments to diagnose developmental delays, disabilities, as well as lack of developmentally and culturally relevant teaching materials. Regression analysis indicated that age, experience, location, and training are important variables explaining perceived benefits of ECD. This study offers researchbased ways to address challenges and threats to effective ECD programs.
\end{abstract}

Keywords: early childhood development, early intervention, exceptionalities, Zimbabwe.

\section{Introduction}

Early Childhood Education (ECE) known in most developing countries as Early Childhood Development (ECD) has now become a global imperative (Dakar Declaration, 2000; NAEYC, 2009; UNESCO, 2009; UNICEF, 2014), because it is vital for all children. The World Education Forum (2000) sets early childhood education as a priority goal for human development in all societies. Research-based evidence indicates that ECE supports developmental gains in language, cognitive, social, and emotional development, and forms the basis for future academic and social success (Eliason \& Jenkins, 2012; Deiner, 2010; UNESCO, 2008). Early intervention is a useful practice in identifying and support children who have developmental delays and various exceptionalities (Turnbul, Turnbull, Wehmeyer \& Shogran 2017). In addition, studies reveal that children who go through formal early childhood education do well in the first and subsequent

(C) Authors. Terms and conditions of Creative Commons Attribution 4.0 International (CC BY 4.0) apply. Correspondence: Arnold Nyarambi, East Tennessee State University, College of Education, Educational Foundations \& Special Education, Johnson City, UNITED STATES. E-mail: anyarambi@gmail.com. 
A. Nyarambi \& E. Ntuli - A study of Early Childhood Development Teachers' Experiences...

grades (Anderson et al., 2003; Bakken, Brown \& Downing, 2017). Most children master the literacy and other foundational skills during early education and that plays a tremendous role in their future learning and academic success (American Federation of Teachers, 2002; Young, 1996). All children, therefore deserve high-quality developmentally appropriate and culturally competent early childhood education; this is very crucial for children from low socio-economic and disadvantaged backgrounds, including those who are at risk and those with various disabilities. The purpose of the study was to examine ECD teachers' perceptions of ECD programs regarding the benefits, threats, and challenges as well as opportunities for early intervention.

\subsection{Literature review}

The philosophy behind Head Start programming in the USA, for example, is the idea of early exposure to foundational knowledge and skills for children from low-socio-economic backgrounds (Gargiulo \& Kilgo, 2020). Research indicates that high quality and effective early education experiences help children from low socio-economic and disadvantaged backgrounds to overcome the influences of poverty (Children's Defense Fund, 2005; Shonkoff \& Phillips, 2000), and early identification and intervention help children with delays, disabilities, and those at risk to minimize or overcome the challenges (Ramey, Campbell, Burchinal, Skinner, Gardner \& Ramey, 2000; Turnbull, Turnbull, Wehmeyer \& Shogren, 2013). For ECE to be implemented effectively, current early childhood research calls for early childhood teachers, caregivers, and all stakeholders to be knowledgeable in the areas of brain development (Gilkerson, 2001; Zambo, 2007), and social-emotional development (Gargiulo \& Kilgo, 2020), for such kind of knowledge leads to developmentally appropriate practices.

Research on brain development indicates that brain growth is most dramatic in the early years before children start formal schooling (Gallagher, 2005). It is during the early years o5 years that rich experiences in the environment adds to the production of more synapses, which leads to brain growth and development (Colbert, 2008). Synapse refers to the connection points between the neurons. The greater the numbers in synapses, the greater the number and variety of messages to travel in the brain; making it possible for massive information processing (Bloom, Nelson \& Lazerson, 2001; McDevitt \& Ormrod, 2016; Tierney \& Nelson, 2009). The synapses could be pruned and jeopardized when children are deprived of rich experiences from the environment, or when the environment does not offer developmentally appropriate learning experiences (Gilkerson, 2001; McDevitt \& Ormrod, 2016). Children from disadvantaged backgrounds may have their synapses pruned early due to a lack of viable conducive learning environment suitable for brain development. Research has indicated that the early years are critical in the formation of intelligence, personality, social behavior, and physical development, and in forming the building blocks for dispositions and attitudes, which will persist throughout life (Hunzai, 2007; Woodhead, 2006). Therefore, early childhood is a critical period where effective early childhood education backed by brain research should be available for all children.

In the United States, where early childhood education is well established, education policy makers provided a platform advocating for early childhood education for all, including disadvantaged children, those with developmental delays and disabilities and that culminated in the inception of Head Start (Gallagher, 2005). Research completed in Head Start programs supports that early education is the time to provide early intervention and mitigate potential problems in children that might hinder learning later when they start first grade and start learning foundational and more challenging concepts. Eliason and Jenkins (2012) summarize the importance of early childhood education by indicating that early education mitigates problems by providing special programs that benefits children who are economically disadvantaged, those who are from poverty backgrounds; those with learning disabilities and other special education needs in inclusive environments. 
Since early childhood is a critical period, there is need for proper training for those who provide early education and early intervention (Eliason \& Jenkins, 2012; Hyson, Tomlinson, \& Morris, 2009). Likewise, Hyson, Tomlinson, and Morris (2009) note, “...a teacher's education, if it is rich and deep and positive, provides a critical foundation that may constructively influence children's experiences" (p. 30). However, research indicates that most early childhood education teachers and caregivers have not gone through proper teacher preparation programs (Tafera, 2018; UNESCO, 2015), this is not only a problem in developing countries, but also in developed countries (Macewan, 2015; Saracho \& Spodek, 2007). Eliason and Jenkins (2012) writing about children in homes where both parents work or from single-parent homes note that "there is a need not only for more childcare programs, but also for upgrading the quality of childcare given. Because many young children are still cared for by untrained caregivers..." (p. 7). Given the importance of ECD, it was important to examine the current status of ECD in Zimbabwe from the perspective of early childhood teachers. In order to situate the purpose of the study, a detailed background of early childhood education in Zimbabwe is outlined next.

\subsection{Early childhood development in Zimbabwe}

ECD programming is fairly new, less than a decade old, in most African countries including Zimbabwe. As recent as 2004, Zimbabwe instituted ECD as a policy directed at all primary schools in order to create at least two ECD classes for children in the 3-5 years age group. The basis for the 2004 policy was a recommendation of the Commission of Inquiry into Education undertaken in 1999 (Nziramasanga, 1999). The Commission found that many children in rural and poor communities did not have access to early childhood services. The aim of the 2004 policy framework was to make official the ECD programs under the Ministry of Education, Sport and Culture (MoESAC), increase equity and access to ECD provisions, and enhance quality education.

Currently, ECD is divided into group $A$ and $B-$ of 3-4 year olds and 4-5 year olds, respectively (MoESC, 2005). The implementation of ECD classes has served as a vehicle to make pre-school education available to all children in Zimbabwe as recommended by the 1999 Presidential Commission of Inquiry into Education (Nziramasanga, 1999). Today, the MoESC fully supports the ECD policy, and follows the global trends in early childhood education; specifically, its advantages in preparing children for elementary/primary schools. The MoESC recognizes that ECD education can contribute significantly to the nurturing of young children's physical, social, emotional, intellectual, cultural, and cognitive abilities. The growth in ECD literature documents the efforts made by the Zimbabwean government alone, and in collaboration with organizations, such as UNICEF, to make ECD formal and available to the public as part of primary school education (Dyanda, 1999; Freitas, Shelton \& Tudge, 2008; UNICEF, 2002; Zimbabwe MoESC, 2001).

The 2004 national ECD policy requires primary schools to offer a minimum of two ECD classes for children from 3 to 5 years old. According to the Southern and Eastern Africa Consortium for Monitoring Educational Quality (SACMEQ) (2017), "ninety eight percent of primary schools are offering ECD classes" (par. 2). In support of this policy, primary teacher training colleges are now training ECD teachers who receive certified diplomas in ECD through the University of Zimbabwe. Universities in Zimbabwe (e.g., University of Zimbabwe and the Women's University in Africa) recently started new education programs in ECD. This new development will change the landscape of early childhood education in the country as graduates from these programs positively affect ECD. At the Women's University in Africa, for example, teacher candidates complete an ECD course that is relevant to exceptional learning (i.e., ECD, 2011: Special Needs Education) during the second year of their Bachelor of Education in the ECD program. As stated on their program website: 
A. Nyarambi \& E. Ntuli - A study of Early Childhood Development Teachers' Experiences...

"The main objective of the course is to create awareness among students on the needs of exceptional children. They should be able to identify as well as facilitate early referral, which subsequently leads to early assessment as well as placement in relevant educational programs offered by the Ministry of Education, Arts, Sport and Culture. This course is in line with the Ministry of Education, Sport and Culture's policy of integration where emphasis is on educating the child in his/her environment whenever possible. Knowledge of different types of exceptional children should also help teachers to design appropriate learning programs that suit a particular child." (Women's University in Africa, 2011)

Such courses equip teacher candidates with relevant knowledge and appropriate skills needed for effective early childhood education. Given all the developments regarding ECD in Zimbabwe, not so much research has been conducted that investigates the utility of ECD programs from the perspective of ECD teachers; specifically what they perceive as benefits, threats and challenges, and how they identify children in need of early intervention.

\subsection{The purpose of the study}

The purpose of the study was therefore, to examine ECD teachers' perceptions of ECD programs regarding the benefits, threats, and challenges as well as opportunities for early intervention. Specifically, this study sought to address the following research questions:

teachers?

(1) What are the benefits of ECD programs in Zimbabwe from the perspective of ECD

(2) Do ECD programs use developmentally appropriate curricula, methods, and intervention strategies that are appropriate for inclusive classrooms?

(3) Do schools have adequate resources for ECD classes?

(4) What are the teachers' perceptions about inclusion in ECD classrooms and ECD teacher training programs in Zimbabwe?

(5) What are the factors explaining teachers' perceptions about ECD programs and benefits in Zimbabwe?

(6) What opportunities can help alleviate the threats and challenges in ECD programs?

\section{Method}

\subsection{Research design}

In this study, a concurrent mixed method approach was employed in two phases. A concurrent mixed method design is a multi-strand design in which qualitative and quantitative data are concurrently collected and analyzed (Tashakkori \& Teddlie, 2003). The first phase of data collection from a purposeful sample of eighty-one ECD participants. In this study, a survey instrument with both open-end and closed-end interview questions was used to collect data in the first phase. In the second phase, qualitative data were collected by way of semi-structured interviews from a typical sample of six key informants. The key informants were purposefully selected teachers with varying teaching training and experience in ECD in the district of Chipinge, in Zimbabwe. A typical sample would be one that is selected because it reflects the average person, situation, or instance of the phenomenon of interest (Merriam, 1998). Interview questions were developed based on the inferences from both qualitative and quantitative data analyses from the first phase. 


\subsection{Participant selection}

The researchers sought permission from the MoESC, headmasters and private owners of ECD programs before issuing paper-based consent forms and surveys to the teachers. The consent forms indicated that the study was voluntary, and by completing the survey, they were giving their consent. However, they were free to withdraw from the study at any time. Teachers were given a week to turn in their completed surveys at the principal's office or the administration office of their ECD program. Two groups of ECD teachers: Those who teach group $A$ (3 years old) and those who teach group $B$ (4-5 years old) sample participants were surveyed from Chipinge district, located in Manicaland province in Zimbabwe. Eighty-one teachers returned viable surveys and became the sample of the study. Out of the eighty-one teachers who took the survey, thirty six teachers had not gone through prior ECD teacher training programs. The sample consisted of 40 group $A$ teachers and 41 group $B$ teachers. Among group $A$ teachers, 20 were urban teachers and 20 were rural teachers; group $B$ had 21 urban and 20 rural teachers. The teachers' ages who were selected and surveyed were between 22 years and 60 years old. The average class size for each teacher was 25 children per class.

\section{Data collection and analysis}

The study used both descriptive and regression analysis techniques to address the questions raised above. The descriptive analysis component comprised of simple tables and graphs showing frequency distributions. We used regression analysis methods to examine the determinants of teacher's perceptions of ECD programs and the associated benefits. Due to the subjective questions that we are asking (i.e., how the dependent variable is measured), we prefer to use a logit model. Alternatively, we can employ multiple regression analysis using ordinary least squares, but the interpretation of the coefficients would not be easy since we are dealing with a variable that is unobservable. We assume that the teacher's perception about ECD programs and benefits is unobservable and thus we ask a number of questions associated with the teacher's perception. To derive the dependent variable, we used factor analysis of the questions associated with the benefits of the ECD program (see Table 2). The variable was rescaled so that it lied between 0 and 100 for easy interpretation. If the dependent variable is 1 , if the index is above 50 and zero otherwise. Thus, the benefits are realized when the index is greater or equal to 50 and hence the dependent variable is 1 , otherwise the benefits are insignificant. The dependent variable is re-defined as follows:

$$
D_{i}= \begin{cases}1 & \text { if } B_{i} \geq 50 \\ 0 & \text { if } B_{i}<50\end{cases}
$$

where $D_{i}$ is a "placebo" variable and $B_{i}$ represents the teacher's perception of ECD program and benefits from ECD learning. To model the relationship between ECD benefits and teacher characteristics, the paper used the logit model and ordinary least squares (OLS) regression for comparison purposes. We assumed that actual ECD benefits are unobservable, but what teachers observe are the variables in Table 3, that is $D_{i}^{*}=X_{i} \alpha+\varepsilon$ and so $D_{i}=1$ if $D_{i}^{*}>0$, which implies that $B_{i} \geq 50$ and zero otherwise. If we assume that $\varepsilon_{i} \sim \Lambda(0,1)$ then:

$$
\operatorname{Pr}\left(D_{i}=1 \mid \mathrm{X}_{\mathrm{i}}\right)=\frac{\exp \left(\mathrm{X}_{\mathrm{i}} \alpha\right)}{1+\exp \left(\mathrm{X}_{\mathrm{i}} \alpha\right)}
$$

It immediately follows that 
A. Nyarambi \& E. Ntuli - A study of Early Childhood Development Teachers' Experiences...

$$
\operatorname{Pr}\left(D_{i}=0 \mid \mathrm{X}_{\mathrm{i}}\right)=1-\frac{\exp \left(\mathrm{X}_{\mathrm{i}} \alpha\right)}{1+\exp \left(\mathrm{X}_{\mathrm{i}} \alpha\right)}
$$

So that the odds ratio becomes

$$
\begin{aligned}
\exp \left(\mathrm{X}_{\mathrm{i}} \alpha\right) & =\frac{\operatorname{Pr}\left(D_{i}=1 \mid \mathrm{X}_{\mathrm{i}}\right)}{\operatorname{Pr}\left(D_{i}=0 \mid \mathrm{X}_{\mathrm{i}}\right)} \\
& =\frac{\pi_{i}}{1-\pi_{i}}
\end{aligned}
$$

Intuitively

$$
\ln \operatorname{odds}\left(D_{i}=1 \mid \mathrm{X}_{\mathrm{i}}\right)=\alpha_{0}+\alpha_{1} \text { Age }+\alpha_{2} \text { Experience }+\alpha_{3} \text { Location }+\alpha_{4} \text { Training }+\varepsilon_{i}
$$

A comprehensive survey of the literature was done to gather key explanatory variables that could be used in the regression model. Experience and location were positively correlated with early childhood education or ECD benefits (Gallacher, 1997; Sheridan, Edwards, Marvin \& Knoche, 2009; Welch-Ross, Wolf, Moorehouse \& Rathgeb, 2006). Sheridan, Edwards, Marvin and Knoche (2009) established that training is positively related with ECD benefits. The variable age had mixed results. Table 1 summarizes the explanatory variables and provides the expected signs.

Table 1. Summary of variables

\begin{tabular}{lll}
\hline Variable & Explanation & Expected sign \\
\hline $\begin{array}{l}\text { Perceived benefits of ECD } \\
\text { Explanatory variables }\end{array}$ & Dependent variable & \\
Age [no. of years] & Age of the respondent & \pm \\
Experience [no. of years] & Teaching experience of the respondent & + \\
Location [o=rural, $1=$ urban] & Location of the respondent & + \\
Training & & + \\
\multicolumn{1}{c}{ Degree } & ECD teacher with degree & + \\
$\quad$ Diploma & ECD teacher with diploma/certificate & Undetermined \\
$\quad$ Nocational training & ECD teacher with vocational training & - \\
\hline
\end{tabular}

\subsection{Instrument}

Subject matter experts assessed content validity of the survey instrument designed for data collection to ensure that the instrument measured what it intended to measure. Content validity is the degree to which a test measures an intended content area or the extent to which a measurement reflects specific intended domain of content (Gay, Mills \& Airasian, 2008). The survey instrument was pilot-tested using a convenient sample of teachers to ensure reliability. Pilot testing helped to determine that the participants of the study would be capable of completing the survey and that they could understand the questions (Cresswell, 2011). The survey allowed the researchers to collect quantitative and qualitative data simultaneously. Closed-end questions included 10 Likert scale items and an environmental checklist with 20 items. The Likert scale provided information about teacher attitudes, and understanding of the benefits of ECD. The checklist provided information about developmental appropriateness of the ECD environmental 
contexts, specifically the physical environment, curriculum, methods, and intervention strategies. Five open-end questions probed more deeply and explored the participant's perspectives and experiences with ECD without constrain. Closed-end questions were analyzed using descriptive statistics and the teacher narratives on open-end questions were coded and analyzed for themes and commonalities as suggested by Saldana (2009). Based on the initial survey results, the researcher selected six participants for one-on-one semi-structured interviews which lasted approximately 45 minutes. Probing questions were used during the interviews in order to access an in-depth understanding of the phenomenon understudy (Patton, 2003). Interviews were transcribed, and data were coded and analyzed for themes and commonalities (Saldana, 2009).

\section{Findings and discussion}

\subsection{Characterization}

Table 2 characterizes the sample of ECD teachers that participated in the survey between May and July 2018. The results show great variability. The mean age of the sample is 44 years, while the average number of years in school (i.e., the mean years they had spent teaching in the school) is 13 years. About 53\% of the respondents were urban ECD teachers and 66\% had received ECD training. The variable for ECD benefits recovered using factor analysis was below 0.5 implying that the perceived benefits were low. This figure could be affected by the huge number of untrained and vocational ECD teachers in the sample.

Table 2. Teacher characteristics

\begin{tabular}{|c|c|c|c|}
\hline Variable & Obs & Mean & Standard deviation \\
\hline Age & 81 & 43.74 & 13.254 \\
\hline Experience [no. of years] & 81 & 4.915 & 2.432 \\
\hline School [no. of years in school] & 81 & 13.025 & 3.125 \\
\hline Location [o=rural, $1=$ urban] & 81 & 0.632 & 0.362 \\
\hline \multicolumn{4}{|l|}{ ECD training } \\
\hline Degree & 10 & 0.128 & 0.012 \\
\hline Diploma & 18 & 0.227 & 0.121 \\
\hline Vocational & 24 & 0.301 & 0.071 \\
\hline No training & 29 & 0.3440 & 0.214 \\
\hline Total & 81 & 0.656 & 0.456 \\
\hline ECD benefits & 81 & 0.4215 & 0.231 \\
\hline
\end{tabular}

Source: survey data

\subsection{Teacher perceptions on the benefits of ECD Education}

Quantitative descriptive analysis of the closed-end questions indicated that a majority of the teachers believed that ECD education was important and necessary for preparing children for later primary school success (see item 1-4 in Table 3). These findings (item 1-4) are similar to what Mushoriwa and Muzembe (2011) found; however, the difference in the current findings is that the majority of teachers did not believe that ECD training provided a strong basis for early intervention (see item 5-8 in Table 3). This is a point of concern because early childhood education should provide early intervention for children who are "at risk" or who have a high probability of developing learning and development disabilities (Deiner, 2012; Gargiulo \& Kilgo, 2011). Also in this study, most ECD teachers were undecided as to whether the curriculum lays a strong foundation for first grade (see item 3) or whether the curriculum they used aligned with what children covered in first grade. This questions the sequencing and connection(s) of ECD curriculum with the 1st grade curriculum at teacher preparation programs. 
A. Nyarambi \& E. Ntuli - A study of Early Childhood Development Teachers' Experiences...

Table 3. Teacher ratings regarding the importance and benefits of ECD

\begin{tabular}{|c|c|c|c|c|c|}
\hline Item & $\begin{array}{l}\text { Strongly } \\
\text { Agree } \\
\text { (\%) }\end{array}$ & $\begin{array}{l}\text { Agree } \\
\text { (\%) }\end{array}$ & $\begin{array}{l}\text { Undecided } \\
\text { (\%) }\end{array}$ & $\begin{array}{l}\text { Disagree } \\
\text { (\%) }\end{array}$ & $\begin{array}{l}\text { Strongly } \\
\text { Disagree } \\
\text { (\%) }\end{array}$ \\
\hline $\begin{array}{l}\text { 1. ECD education is important and } \\
\text { necessary to all children. }\end{array}$ & 95 & 5 & 0 & o & 0 \\
\hline $\begin{array}{l}\text { 2. ECD prepares children for later } \\
\text { primary school success (e.g. success } \\
\text { in } 1^{\text {st }} \text { Grade) }\end{array}$ & 80 & 10 & 10 & o & o \\
\hline $\begin{array}{l}\text { 3. The ECD curriculum for A and B } \\
\text { classes lays a strong foundation for } \\
1^{\text {st }} \text { Grade }\end{array}$ & 5 & 35 & 60 & o & o \\
\hline $\begin{array}{l}\text { 4. Children who go through ECD } \\
\text { have less difficulties adjusting to } \\
\text { formal schooling. }\end{array}$ & 75 & o & 20 & 5 & o \\
\hline $\begin{array}{l}\text { 5. Children with special needs are } \\
\text { identified early during ECD }\end{array}$ & o & o & 40 & o & 60 \\
\hline $\begin{array}{l}\text { 6. ECD provides positive behavior } \\
\text { supports for children at risk of } \\
\text { behavioral problems in 1st Grade. }\end{array}$ & 10 & 10 & 20 & o & 60 \\
\hline $\begin{array}{l}\text { 7. Children with special needs who } \\
\text { go through ECD are likely to do } \\
\text { better in academic work. }\end{array}$ & 80 & 10 & o & 10 & o \\
\hline $\begin{array}{l}\text { 8. Early intervention is provided } \\
\text { through ECD. }\end{array}$ & O & o & 10 & 50 & 40 \\
\hline
\end{tabular}

Source: survey data

\subsection{Teacher knowledge and skills of ECD curriculum}

Teachers rated their levels of knowledge and skills regarding ECD curriculum (see Table 4). More than seventy percent of the teachers indicated that they were either not sure (for instance; undecided, disagreed, or strongly disagreed) of the curriculum. 


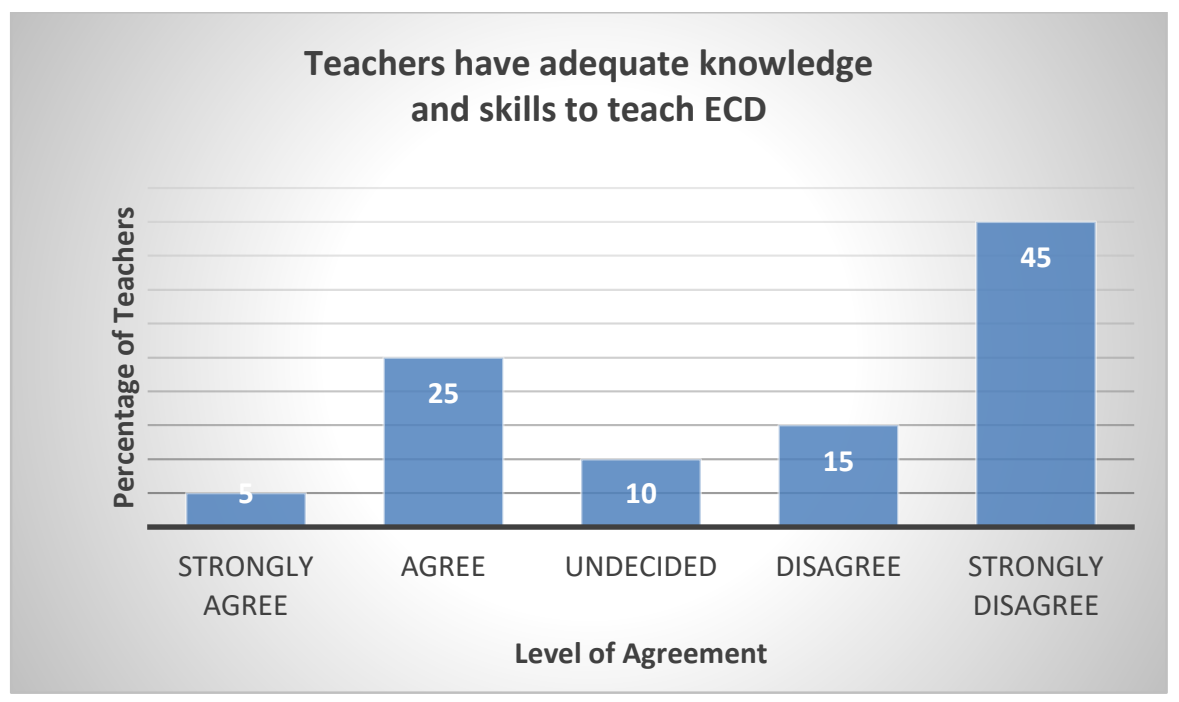

Source: survey data

Figure 1. Teacher ratings regarding their level of knowledge and skills of ECD curriculum

Figure 1 shows that most respondents, about 45\%, strongly disagreed with the idea that teachers had adequate knowledge and skills of ECD curriculum. Disaggregating the results by number of years in teaching and location, Figure 1a shows that experienced teachers in urban areas believed that they had the required knowledge and skills of ECD curriculum. This could be because those teaching in urban areas attended more professional development. Analysis by category of teacher revealed that teachers with no training were the majority who strongly disagreed that they had the knowledge and skills of ECD curriculum, followed by those who went for vocational training, whose majority were uncertain (see Figure $2 b$ ).

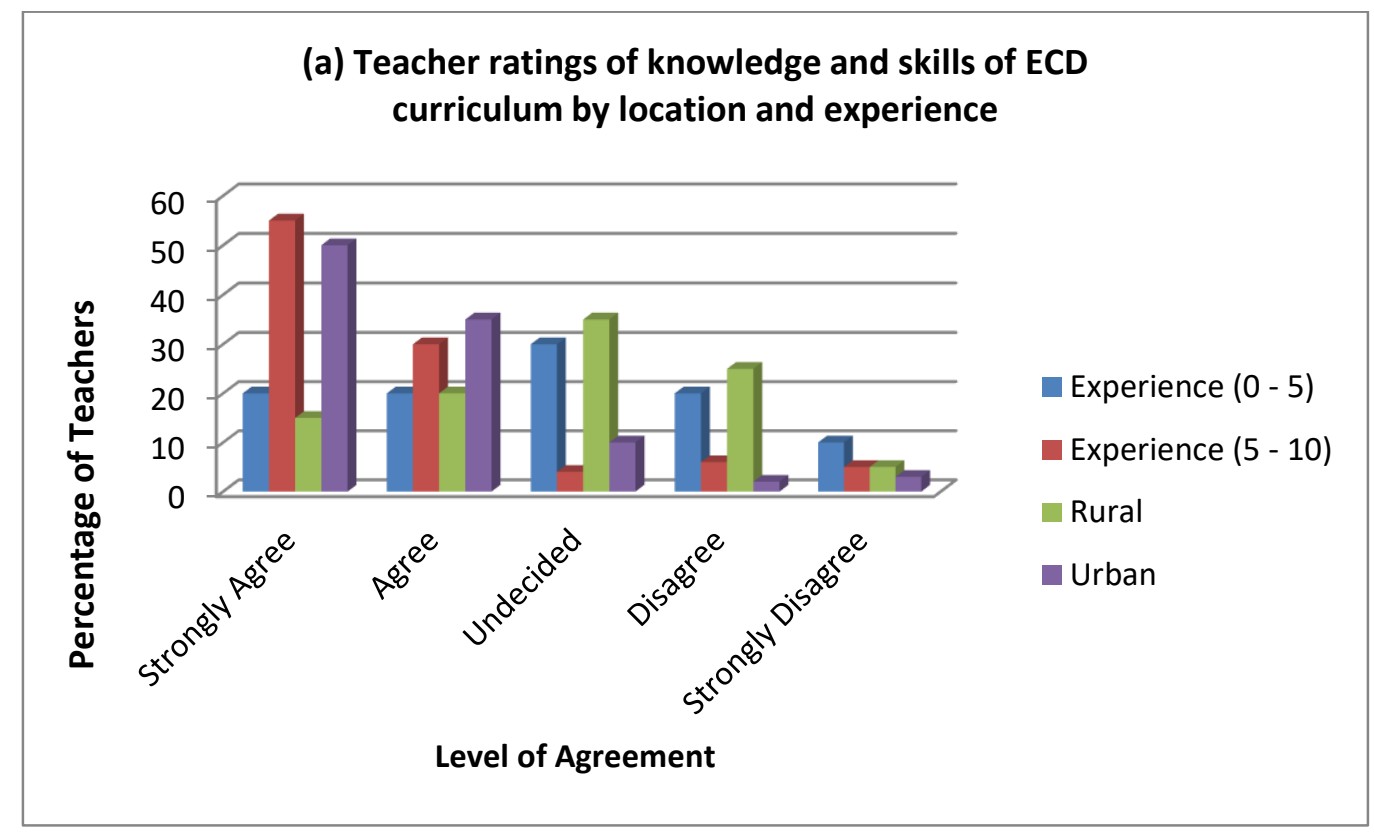


A. Nyarambi \& E. Ntuli - A study of Early Childhood Development Teachers' Experiences...

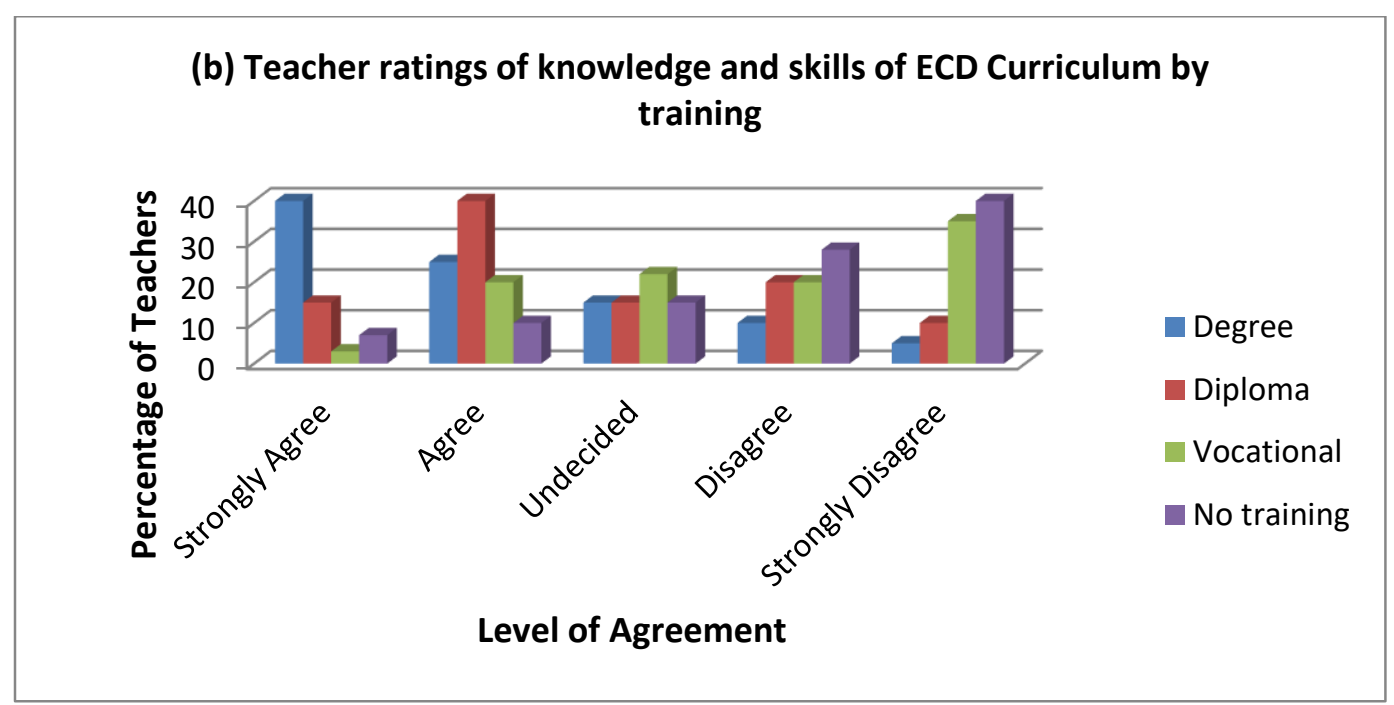

Source: survey data

Figure 2. Teacher ratings of knowledge and skills of ECD curriculum

Data in Figure 1 was corroborated by qualitative data from the open-end questions and interviews, where most teachers indicated that they had not gone through extensive formal training. One teacher said:

I have gone to the training several times but I cannot say for sure if what I know [curriculum] is preparing them [children] well for grade one...for us working with Group A [ 3-4 year olds ] they do not require a diploma or degree...

Another teacher said:

I have not gone to college but to workshops.... I ask other ECD teachers what they are teaching and that is what I do with my children. ...yes, I follow curriculum books but sometimes we do not have materials listed in the books...They come to supervise what we do with children no one has ever said anything...I think we are doing well.

One Group $B$ teacher said:

I have a diploma from [...Teacher's College]. We learnt a lot about children and how they develop...The books that we are using in this school are different from what we used in college...sometimes it is difficult to figure out the connection between what we learnt and what we are supposed to do with these children. I took one course in special education...We did not use any assessments on our own to diagnose students who need early intervention.

Another teacher said:

...in college we did not have students to practice what we were learning. At the moment I am learning on the job...none of the things that we were learning work. After our teaching practice [Field Experience] some [teacher candidates] raised the concern ...I am not sure if some of our lecturers were trained to teach ECD or first grade and up...you never know.

Qualitative data indicates that ECD teacher training and professional development programs grappled to offer high quality curricula that equip teachers with proper child development knowledge and skills. Some teachers found it difficult to connect theory to practice. If early education served to prepare children for future success, help to identify those who needed early intervention, and give the necessary skills to those children from disadvantaged background, 
then ECD teachers should be better prepared. Research indicates that when early childhood teachers go through quality and comprehensive teacher education programs, are equipped with child development knowledge and skills, and exhibit appropriate disposition and behavior, they positively impact children's development and learning (Hyson, Tomlinson \& Morris, 2011; Wilson, Pianta \& Stuhlman, 2007).

\subsection{Do schools have adequate resources for ECD classes?}

Table 4a shows the variables that were collected as part of an environmental checklist adapted from Early Childhood Environmental Rating Scale (Harms, Clifford \& Cryer, 2015). A descriptive analysis of the environmental checklist (see Table 4b) indicates that most ECD classroom and outdoor learning environments did not have adequate teaching and learning materials, good sanitation, meals, and appropriate accommodation for children with learning disabilities.

Table 4a. Environmental checklist

\begin{tabular}{|c|c|}
\hline Space and Furnishings & $\begin{array}{l}\text { 1.Furnishings for relaxation and comfort (e.g. beds, blankets, etc) } \\
\text { 2. Space for gross motor play } \\
\text { 3. Gross motor equipment } \\
\text { 4. Indoor space } \\
\text { 5. Furniture for routine care, play, and learning (e.g. little chairs and } \\
\text { tables that are at the level of children, toys) }\end{array}$ \\
\hline Personal Care Routines & $\begin{array}{l}\text { 7. Meals/snacks } \\
\text { 8. Nap/rest } \\
\text { 9. Toileting (e.g. toilet papers, washing soap, diapers, etc) }\end{array}$ \\
\hline Sanitation & $\begin{array}{l}\text { 10. Toilets for children separate from adults } \\
\text { 11. Clean Water } \\
\text { 12. Sinks (or places to was hands) }\end{array}$ \\
\hline Teaching materials & $\begin{array}{l}\text { 13. Developmentally and culturally appropriate reading books } \\
\text { 14. Stationary (e.g. crayons, note parts, art books, etc.) }\end{array}$ \\
\hline Program Structure & $\begin{array}{l}\text { 15. Accommodations and provisions for children with disabilities } \\
\text { 16. Provisions for parents (e.g. Information) } \\
\text { 17. Opportunities for professional growth } \\
\text { 18. Supervision and Evaluation of ECD Staff (e.g. ECD are frequently } \\
\text { observed, and supervision is given is a helpful). }\end{array}$ \\
\hline
\end{tabular}

Source: Harms, Clifford \& Cryer (2015). Early childhood environmental rating scale.

Table 4b. Environmental checklist to determine the appropriateness of ECD environments

\begin{tabular}{llllll}
\hline Item & \multicolumn{5}{c}{ Percent of Teachers } \\
\cline { 2 - 6 } & Inadequate & Minimal & Good & Excellent & Total \\
\hline Space and Furnishings & 70 & 0 & 20 & 10 & 100 \\
Personal Care Routines & 60 & 0 & 40 & 0 & 100 \\
Sanitation & 90 & 0 & 10 & 0 & 100 \\
Teaching materials & 70 & 0 & 20 & 10 & 100 \\
Program Structure & 80 & 0 & 10 & 10 & 100 \\
\hline Overal & $\mathbf{7 4}$ & $\mathbf{0}$ & $\mathbf{2 0}$ & $\mathbf{6}$ & $\mathbf{1 0 0}$ \\
\hline
\end{tabular}

Source: survey data 
A. Nyarambi \& E. Ntuli - A study of Early Childhood Development Teachers' Experiences...

The results from the environmental checklist indicate that ECD environments were poorly equipped. Lack of sanitation was a devastating issue found to be an overarching theme in the study conducted by Rwatirera, Ngweni and Dhlomo (2011), which focused on rural primary schools. The current study included both urban and rural participants, and findings indicate that the issue of sanitation was not peculiar to rural schools. There was poor sanitation even in urban schools; only $10 \%$ of the teachers from urban schools indicated that they had good sanitation. According to Adams, Bartram, Chartier and Sims (2009), children's ability to learn may be affected by inadequate water, sanitation, and hygiene condition, and this is profound when there are students with disabilities in the school where there is no universal design of the environments. Adams et.al note that, "Toilets that are inaccessible often mean that a disabled child does not eat or drink all day to avoid needing the toilet, leading to health problems...thereby dropping out of school" (p. 5). For other materials such as furniture, toys, and books, teachers can improvise and use what they have locally; however, that is not true for sanitation. If there is no clean water, inadequate toilets, and other sanitation materials such as soap or washing basins, there is little that teachers can do. Most of the boreholes or wells for clean water were donor funded (Gunhu, Mugweni \& Dhlomo, 2011) - one of the leading donor (International Development Agent) in Zimbabwe and Africa in general is UNICEF. Due to lack of funding, schools do not repair boreholes once they break down.

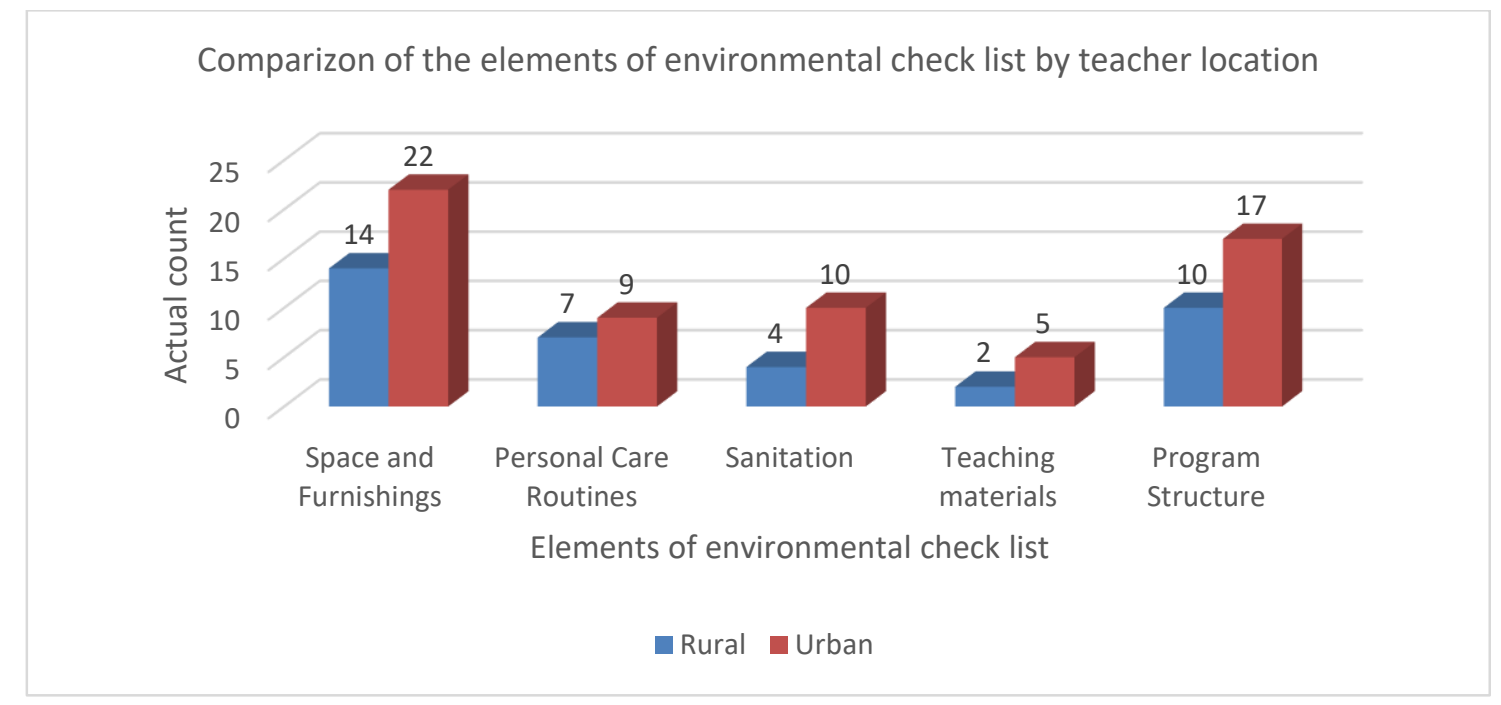

Source: survey data

Figure 3. Comparison of the elements of environmental check list by teacher location (actual count)

\subsection{Lack of parental involvement}

Accumulated research indicates that parental involvement in children's programs is critical to the educational success of children (Daniel, 2009; Kniepkamp, 2005; Kostelnik, Soderman \& Whiren, 2011, Turnbull et. al., 2019). SACMEQ (2017) reports that in Zimbabwe "Workshops for parents to appreciate the importance of ECD education have been conducted country wide" (par. 2). Parents may appreciate the value of ECD without understanding that their involvement is crucial. The findings indicate that parents are not involved much in the education of their children especially in rural areas (see Figure 2). The program structure as indicated in Table 5a shows that the ECD programs did not stipulate the level of parental involvement, neither were parents well informed about the ECD program. The qualitative findings present a different picture. It is not the problem of teachers not sharing information with parents, but the parents' 
attitudes and beliefs about their involvement in their children's education. Many teachers indicated that parents believed that they did not have to help the teacher since teachers received salaries to do their jobs, and some felt they could not help because they did not have the knowledge to teach children. One urban teacher said:

Parents never come in to the classroom to help. They wait outside when they bring the child or when they come to take the child home...

Another teacher said:

I have never met the parent...the maid brings the child to school...

Teachers in rural schools indicated that children came with their older siblings to school and there was no chance of meeting parents as they were involved in subsistence farming or harvesting. One rural teacher said:

Most children come to school with their older siblings...the only time you get to meet the parent is when they come to register the child or when there is a school development association (SDA) meeting.

Another teacher said:

Children from different compounds walk in groups and there is no need for parents to bring them to school...they protect each other...their parents work in tea estates [picking tea].

Only thirty-percent of the teachers rated the level of parental involvement to be good. These teachers were urban teachers. However, qualitative data provided a different insight. Though 30\% of the urban teachers indicated that ECD parents were involved in the education of their children, the quality of involvement was not what research recommends in developmentally appropriate practices in early childhood education. Research recommends that parents should collaborate with teachers to design interventions extended from school to the home environment (Fettig \& Ostrosky, 2011), assist children with homework in order to internalize the material completed in class by going through the activities several times on a daily basis, particularly with difficult concepts. Instead, urban parents, as reported by ECD teachers, got involved to organize events such as end-of-year Christmas parties, birthday parties, and other events which were not related to the teaching and learning of the children. One teacher said:

Many parents come to help during parties like if their child has a birthday or if we are having parents' day...some come for prize-giving day.

Another said:

I have seen many parents helping to organize Christmas party ...some parents come because they want their child to be in a Christmas play...

Meaningful parental involvement goes beyond participating in special events; rather, there should be a strong partnership and collaboration between parents and teachers. Research indicates that successful inclusive early childhood professionals collaborate with parents in the designing and implementation of their children's curricula (Eliason \& Jenkins, 2012; Kostelnik et al., 2011). Parents know their children better and their contributions to the curriculum strengthens the quality of teaching strategies and individualized materials to be used by the teacher (Copple \& Bredekamp, 2009). Successful early childhood programs collaborate with parents and encourage parents to teach their children at home as a way to help children increase cognitive and adaptive skills across different environments (Henninger, 2009; Widerstrom, 2005). Partnership and collaboration between families and professionals during early childhood years have several benefits including enhancing the family's quality of life, and gains in child skills such as language, self-help, social, motor pre-academic skills, etc. (Turnbull, Turnbull, Wehmeyer \& Shogren, 2013). 
A. Nyarambi \& E. Ntuli - A study of Early Childhood Development Teachers' Experiences...

\subsection{Regression analysis}

In this section, a simple logit model was used to analyze the factors explaining the teacher's perception of ECD programs and associated benefits. Several tests were conducted to confirm the validity of the model in question. The results in Table 5 indicate that the model explains about $53.7 \%$ of the variation in the dependent variable. The results show that being an urban ECD teacher increased the probability of perceiving ECD as beneficial. Again, experienced teachers had a higher probability of perceiving ECD as beneficial. The probability of perceived ECD benefits is higher for trained ECD teachers with degrees and diplomas than it is for untrained ECD teachers (no training is used here as the base category). Furthermore, the coefficient for vocational trained teachers is insignificant suggesting that there could be no significant difference between vocational training and no training, i.e., the training given to vocational trained ECD teachers was inadequate.

Based on the regression results, several policy implications can be drawn. In the shortrun, there is need for policymakers to design comprehensive training programs for vocational and untrained teachers tailor made to suit their needs and equip them with the knowledge, technical skills, and theory of ECD programs, while at the same time increasing the contact hours with the trainees. In the long-run, all untrained and vocational trained teachers should undergo training similar to a certificate or diploma in ECD. Furthermore, the trained teachers should frequently attend professional development refresher courses in order for them to stay updated with advances in the field.

Table 5. Logit model results (Dependent variable: Perceived ECD benefits)

\begin{tabular}{lc}
\hline Explanatory variables & Logit \\
\hline Age & $0.026^{* *}$ \\
& $(0.924)$ \\
Experience & $0.642^{* *}$ \\
& $(0.748)$ \\
Location & $0.083^{* * *}$ \\
& $(0.809)$ \\
Degree & $0.736^{* * * *}$ \\
& $(0.936)$ \\
Diploma & $0.64^{* * *}$ \\
& $(1.816)$ \\
Vocational & -0.260 \\
& $(0.568)$ \\
Constant & $0.881^{*}$ \\
& $(0.706)$ \\
\hline Pseudo $R^{2}$ & 0.537 \\
L R Chi2 () & 19.45 \\
Prob $>$ Chi2 & 0.0016 \\
Observations & 81 \\
\hline Source: survey data & \\
* $10 \%$ significance level, ${ }^{* *} 5 \%$ significance level, & $* * * * 1 \%$ significance level
\end{tabular}

\section{Summary of findings}

Based on the findings, ECD teachers perceived early childhood education to be beneficial to children's development, and that it could afford opportunities for early intervention, and lay the building blocks for future success. However, the teachers agreed that the ECD teacher training programs were not offering enough preparation on strategies and early intervention for children with disabilities. In addition, schools did not have enough infrastructure to provide 
developmentally appropriate curricula. Therefore, inclusive education in ECD classrooms is not effectively implemented.

Regression analysis results confirmed that being an urban ECD teacher increased the probability of perceiving ECD as beneficial. Furthermore, experienced teachers had a higher probability of perceiving ECD as beneficial. The probability of perceiving ECD as beneficial was higher for trained ECD teachers, with a diploma or degree, than it is for untrained ECD teachers (the no training is used here as the base category or reference upon which we compare the other three categories), while the results for vocational trained teachers are insignificant. This result seem to suggest that there is little difference between untrained and vocational trained teachers in terms of the teacher's perception of ECD programs and associated benefits.

\section{A way forward}

In order for ECD to be more effective in Zimbabwe, there is need for those who form education policies, and other stakeholders to review the early childhood teacher preparation curriculum. The curriculum should include the provision of early childhood exceptional education. There is need to infuse culturally relevant and culturally responsive curricula at the pre-service teacher preparation stage in order to produce ECD teachers who are self-sufficient and are able to improvise depending on the cultural context and socio-economic level that they find themselves in. A curriculum that teaches ECD teachers to improvise and make toys and other materials from locally available cheap materials would be more effective as this curriculum would teach ECD teacher candidates to use locally available materials to develop culturally relevant teaching materials. This takes into consideration the educational funding challenges that Zimbabwe is currently experiencing.

There is need for continuous ECD professional development through workshops to enhance the skills of those who are already working as temporary teachers without a relevant teaching qualification. These workshops should be geared towards teaching ECD teachers culturally relevant curriculum, child development, information on exceptionalities, early childhood teaching methods and strategies, early intervention assessment and skills, and development of partnerships with parents. This will help in providing quality to ECD programs especially those in rural areas and this benefits children with exceptionalities to receive appropriate education.

Policy makers and other stakeholders should be encouraged to work closely with nongovernmental organizations (NGOs) as they can provide new opportunities for ECD. Most NGOs have new knowledge from working in other countries where they have established ECD. Policy makers and stakeholders should be willing to embrace new ideas, and adapt it to suite their own contexts. In most African countries they frown upon Western or European ideas saying they want homegrown ideas (Ebrahin, 2012; Nsamenang, 2007). Though this is understandable, the danger with this view is that, either some poor countries in Southern Africa do not have enough resources to conduct and develop effective research or it could be an issue of prioritization of available resources. It is encouraged to analyze trends in early childhood education globally (including efforts in other developing countries not only from Africa but Asia and The Pacific, Latin America, etc., to evaluate the possibility of importing culturally competent models. Adopting and importing what works for other countries is the beginning point and implementation should take into consideration cultural and geo-political differences and sensitivities. ECD teacher candidates should adapt to curriculum materials to suit different contexts. This emanates from the fact that within each African country, the cultures, and contexts are so diverse. 
A. Nyarambi \& E. Ntuli - A study of Early Childhood Development Teachers' Experiences...

\section{Acknowledgements}

This research did not receive any specific grant from funding agencies in the public commercial, or not-for-profit sectors.

The authors declare no competing interests.

\section{References}

Adams, J., Bartram, J., Chartier, Y., \& Sims, J. (2009). Water, sanitation and hygiene standards for schools in low-cost settings. Geneva: World Health Organization (WHO). Retrieved from www.who.int/water_sanitation_health/publications/wash_standards school.pdf.

Anderson, L. M., Shinn, C., Fullilove, M. T., Scrimshaw, S. C., Fielding, J. E., Normand, J., et al. (2003). The effectiveness of early childhood development programs: Asystematic review. American Journal Preventive Medicine, 24(3), 32-46.

Bakken, L., Brown, N., \& Downing, B. (2017). Early childhood education: The long-term benefits. Journal of Research in Early Childhood Education, 31(2), 255-269.

Bloom, F. E., Nelson, C. A., \& Lazerson, A. (2001). Brain, mind, and behavior ( ${ }^{\text {rd }}$. Ed.). New York: Worth.

Colbert, J. (2008). Making a difference. Building emotional intelligence for lifetime. Retrieved from http://www.earlychildhoodnews.com/earlychildhood/article_view.aspx?ArticleID=245.

Creswell, J. W. (2008). Educational research: Planning, conducting, and evaluating quantitative and qualitative research ( $3^{\text {rd }}$ ed). Upper Saddle River, NJ: Pearson Education, Inc.

Deiner, P. L. (2010). Inclusive early childhood education: Development, resources and practice (5 ${ }^{\text {th }}$ Ed.). Belmont: CA, Wadsworth, Cengage Learning.

Ebrahim, H. (2012). Tensions in incorporating global childhood with early childhood programs: The case of South Africa. Australasian Journal of Early Childhood, 37(3), 80-86.

Eliason, C., \& Jenkins, L. (2008). A practical guide to early childhood education Curriculum (9 ${ }^{\text {th }}$ Ed.). New Jersey: Pearson Education, Inc.

Fettig, A., \& Ostrosky, M. M. (2011). Collaborating with parents in reducing children's challenging behaviors: Linking functional assessment to intervention. Child Development Research. 2011(2011). http://doi.org/10.1155/2011/835941

Freitas, L. B. L, Shelton, T. L., \& Tudge, J. R. H. (2008). Connections of US and Brazilian early childhood care and education: A historical and comparative analysis. International Journal of Behavioral Development, 32(2), 161-170.

Gallacher, K. K. (1997). Supervision, mentoring, and coaching: Methods for supporting personnel development. In P. J. Winton., J. A. McCollum \& C. Catlett (Eds.), Reforming personnel preparation in early intervention: Issues, models, and practical strategies (pp. 191-213). Baltimore: Paul H. Brookes

Gallager, K. C. (2005). Brain research and early childhood development: A primer for developmentally appropriate practice. Young Children, 6o(4), 12-20.

Gargiulo, R. M., \& Kilgo, J. (2011). Young children with special needs: Birth through age eight. Clifton Park, NY: Thomson/Delmar Learning.

Gargiulo, R. M., \& Kilgo, J. (2020). ( $5^{\text {th }}$ Ed). An introduction to Young children with special needs: Birth through age eight. Thousand Oaks, CA: SAGE. 
Gay, L., Mills, G., \& Airasian, P. (2008). Educational research: Competencies for analysis and application. $9^{\text {th }}$ Ed. Upper Saddle River: Prentice-Hall.

Gunhu, G.M., Mugweni, M. R., \& Dhlomo, T. (2011). Integrating early childhood development (ECD) into mainstream primary school education Zimbabwe: Implications to water, sanitation and hygiene delivery. Journal of African Studies and Development, 3(7), 135-143.

Harms, T., Clifford, R. M., \& Cryer, D. (2015). Early childhood environmental rating scale. Amsterdam Ave, NY: Teacher College Press.

Henninger, M. L. (2009). Teaching young children: An introduction ( $5^{\text {th }}$ Ed.). Boston, Pearson Education, Inc.

Kostelnik, M. J., Sodernam, A. K., \& Whiren, A. P. (2011). Best practices in early childhood education. New Jersey: Upper Saddle River.

Macewan, A. (2015). Early childhood education, economic development, and the need for universal programs: With a focus on New England. Economic, Management \& Financial Markets, 1O(1), 11-47.

McDevitt, T., \& Ormrod, J. (2016). Child development and education (6 ${ }^{\text {th }}$ Ed.). Boston: Pearson Publishing, Inc.

Merriam, S. B. (1998). Qualitative research and case study applications in education. CA, San Francisco: Jossey-Bass.

MOESC (2001). Education for all: Towards 2015. Harare, Zimbabwe: Government Printers.

Mushoriwa, T. D., \& Muzembe, H. P. (2011). Attitudes of primary school teachers towards early childhood development in Zimbabwe primary schools. International Journal Educational Studies, 3(2), 117-127.

Nsamenang, A. B. (2007). A critical peek at early childhood care and education in Africa. Child Health and Education, 1(1), 1-12.

Nziramasanga, C. T. (1999). Commission of inquiry into education and training. Harare, Zimbawe: Ministry of Education, Sport and Culture.

Ramey, C. T., Campbell, F. A., Burchinal, M., Skinner, M. L., Gardner, D. M., \& Ramey, S. L. (2000). Persistent effects of early childhood education on high-risk children and their mothers. Applied Developmental Science, 4(1), 2-14.

Saracho, O. N., \& Spodek, B. (2007). Early childhood teachers' preparation and the quality of program outcomes. Early Child Development Care, 177(1), 71-91.

Sheridan, S. M., Edwards, C. P., Marvin, C. A., \& Knoche, L. L. (2009). Professional development in early childhood programs: Process issues and research needs. Early Education and Development, 2O(3), 377-401.

Tashakkori, A. \& Teddlie, C. (2003). Handbook of mixed methods in social \& behavioral research. Thousand Oaks: Sage.

Tefera, B. (2018). Early childhood care and education (ECCE) in Ethiopia: Developments, research, and implications. Eastern African Social Science Research Review, 34(1), 171-206.

The Southern and Eastern Africa Consortium for Monitoring Educational Quality (2017). Zimbabwe education fact sheet. Retrieved from http://www.sacmeq.org/?q=sacmeqmembers/zimbabwe/education-fact-sheet.

Tierney, A. L., \& Nelson, C. A. (2009). Brain development and the role of experience in the early years. Zero to Three, $30(2), 9-13$.

Turnbull, A., Turnbull R., Wehmeyer, M. L., \& Shogren, K. A. (2013). Exceptional lives: Special education in today's schools ( $7^{\text {th }}$ Ed). Upper Saddle River: Pearson. 
A. Nyarambi \& E. Ntuli - A study of Early Childhood Development Teachers' Experiences...

Turnbull, A., Turnbull, R., Wehmeyer, M. L., \& Shogren, K. (2017). Exceptional lives: Special education in today's schools ( $9^{\text {th }}$ Ed).Upper Saddle River, NJ: Merrill.

UNESCO (2008). The contribution of early childhood education to a sustainable society. Retrieved January 8, 2017, from http://unesdoc.unesco.org/images/0015/001593/159355e.pdf.

UNESCO (2015). A review of the literature: Early childhood care and education (ECCE) personnel in low and middle - income countries. Retrieved 10 March 2018, from http://unesdoc.unesco.org/images/o023/002349/234988E.pdf.

UNICEF (2000). We are also human beings: A guide to children's rights. New York: UNICEF.

UNICEF (2002). Child care practices in Zimbabwe: Harare, Zimbabwe: UNICEF.

UNICEF (2014). Early childhood development: Disabilities. Retrieved from, http://www.unicef.org/disabilities/index 65317.html.

Welch-Ross, M., Wolf, A., Moorehouse, M., \& Rathgeb, C. (2006). Improving connections between professional development research and early childhood policies. In M. Zaslow \& I. MartinezBeck (Eds.), Critical issues in early childhood professional development (pp. 369-394). Baltimore: Paul H. Brookes.

Women's University in Africa (2011). Bachelor of education (Early Childhood Development). Retrieved from,

http://www.wua.ac.zw/index.php?option=com content\&view=article\&id=17\&Itemid=18. 